\title{
Rerum novarum cupidus. Claves para la creación de nuevos entornos para la Educación ${ }^{1}$
}

\author{
Enric Mallorquí-Ruscalleda \\ California State University-Fullerton \\ Rosabel Roig-Vila \\ University of Alicante
}

Notandum 44-45 (mayo-diciembre 2017)
Título: "Nuevos escenarios de enseñanza-aprendizaje. Investigación e innovación".
Coordinadores: Enric Mallorquí-Ruscalleda (California State University-Fullerton) y
Rosabel Roig Vila (University of Alicante)
Ad hoc editor: Rosabel Roig-Vila (University of Alicante)

La Educación, el acceso y, al mismo tiempo, la creación, el desarrollo y la transmisión del conocimiento y valores, ha sido siempre compañera -a veces no muy bien tratada por los poderes - del desarrollo de la sociedad, es más, de la Humanidad. La Educación, como hiperónimo, y en todos y cada uno de sus componentes, ámbitos estructurales, niveles, agentes y vectores, usuarios, profesionales y beneficiarios, ha sido, es y será consustancial a la misma creación de conocimiento, de innovación concreta y conferidora de técnicas y estrategias para su transferencia a la sociedad.

La Historia de la Educación es la historia, al mismo tiempo, de la evolución misma del conocimiento. Se habla de las varias revoluciones tecnológicas habidas en la historia de la Humanidad, siempre ligadas a grandes innovaciones tecnológicas y conceptuales. Y ello desde la misma aparición de la escritura, conferidora de la carta de naturaleza a la "historia" como tal. En tales revoluciones la Educación ha estado más que presente, bien porque se haya gestado tal revolución con los conocimientos adquiridos en el sistema educativo -si se nos permite el anacronismo inherente a la utilización de este concepto por lo que respecta a revoluciones dadas en siglos pasados - o en él se han desarrollado sus consecuencias, permitiendo en gran medida la gestación del paso a la revolución cultural o tecnológica siguiente.

\footnotetext{
${ }^{1}$ Este estudio, así como el conjunto del presente monográfico, se ha desarrollado en el seno del Institut Superior d'Investigació Cooperativa IVITRA [ISIC-IVITRA] de la Generalitat Valenciana (Programa de la Generalitat Valenciana per a la Constitució i Acreditació d'Instituts Superiors d'Investigació Cooperativa d'Excel-lència [Ref. ISIC/012/042]), y en el marco de los sigüientes proyectos de investigación competitivos: «Continuación de la Gramática del Catalán Moderno (1601-1834)» (Ref. FFI2015-69694 [MINECO/FEDER]); «Constitució d'un corpus textual per a una gramàtica del català modern (Gcm)» (IEC [PT 2012-S04-MARTINES]); Digicotracam (Programa PROMETEU per a Grups d'Investigació en I+D d'Excel-lència, Generalitat Valenciana [Ref.: PROMETEOII-2014-018], financiado por el FEDER de la UE; y el grupo de investigación "Educación y Tecnologías de la Información y la Comunicación - Atención a la diversidad. Escuela Inclusiva) [EDUTIC-ADEI] (Universidad de Alicante, VIGROB-039)".
} 
La Educación ha evolucionado con la innovación. No se trata de caer rendidos a los pies de lo nuevo por el simple hecho de serlo. Se trata de tener en cuenta la traditio educativa y poder trazar un rumbo seguro que nos haga poder exprimir lo mejor de la innovación. Para ello nada mejor que la investigación basada en la excelencia del profundo conocimiento de la materia y de las realidades educativas en la completa naturaleza de sus múltiples niveles y facetas.

Somos conscientes de que debemos mejorar sensiblemente los entornos educativos, para que difieran del que nos muestra, por ejemplo, esta magnífica iluminación de Laurentius de Voltolina, de mediados siglo XIV (fig. 1). Nos muestra una lección "proferida" -literalmente, además - unívoca y unilateralmente ex cathedra por el profesor en un aula bien provista de alumnos. Éstos, sin embargo, están sentados en bancadas inmóviles, que poca posibilidad ofrecen de interactuaciones o interlocuciones docente-discente; unos alumnos atienden al profesor sin ningún material de apoyo; otros, consultan un breviarium o vademecum ('manual') con las explicaciones de la materia; otro, situado en $3^{\text {a }}$ fila, al lado de la ventana, toma apuntes -hecho éste que nos indica que estamos en un entorno prerrenacentista como es la gran Universidad de Bolonia, "la dotta", la universidad como tal más antigua de Occidente-; bastantes hablan entre sí, sin atender ni al profesor, ni al manual, ni toman apuntes; e incluso uno comparece dormido.

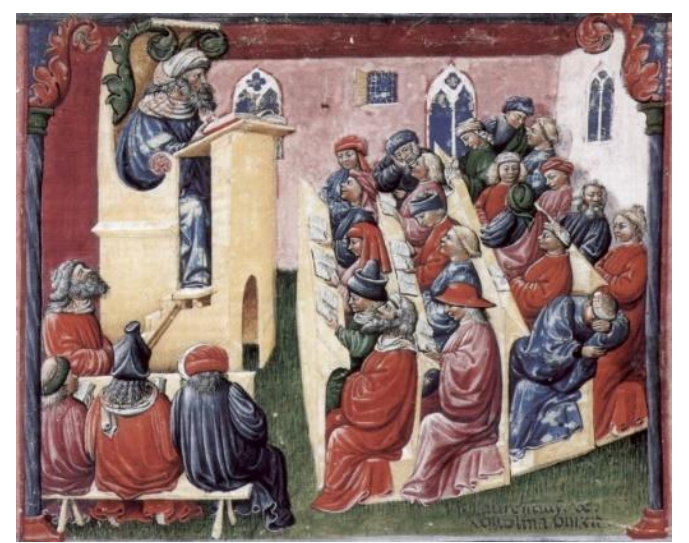

Fig. 1. Iluminación de Laurentius de Voltolina en el Liber ethicorum des Henricus de Alemannia. En Kupferstichkabinett SMPK, Berlin/Staatliche Museen Preussiischer Kulturbesitz, Min. 1233

Quizá se deba poder llegar a un entorno menos unívoco, más vivo, más libre y al mismo tiempo más sujeto al imperio del conocimiento como el incluido en la emblemática obra maestra que es el fresco de Rafael Sanzio que representa la Academia de Atenas, en los Museos Vaticanos (fig. 2). Este fresco del siglo XV, en pleno y desbordante Renacimiento, es toda una declaración de la admiración que despertaron los filósofos - científicos e intelectuales - de la Grecia clásica: Sócrates, Platón, Aristóteles y el resto de esa especie de "generación de mentes extraordinarias" que revolucionaron el mundo, con sus conocimientos, con la innovación que generaron y con la enseñanza de los mismos. 


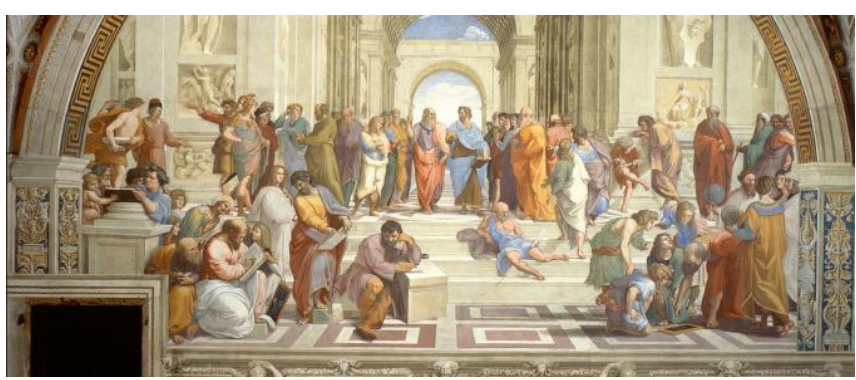

Fig. 2. Rafael Sanzio. Museos Vaticanos.

La Educación ha sido compañera del imperio del conocimiento y de los valores. Y, si lo ha sido, es y será, es porque se constituye en el entorno o hábitat que ha ido evolucionando junto con el mismo conocimiento y formación que ha creado o concitado a crear y a transferir a la sociedad. Se trata de algo de obligado cumplimiento, siempre evolucionar -mejor innovando-. Debemos concitar que el ámbito educativo sea un hábitat idóneo en el que podamos decir "rerum novarum cupidus" -si se nos permite sentir el deseo que expresa Salustio referido a Catalina (Catilina, 28.4), si bien no en cuanto a vanos intereses políticos como en tal conjuración de Catilina, sino aplicado 'la deseo y la estima de lo nuevo' en Educación-.

Así, el presente monográfico primero atiende una perspectiva detallada de la Educación -superior - entre lo real y lo virtual para establecer una trayectoria no lineal en torno a la didáctica universitaria (Jesús Salinas y Victoria I. Marín). Sigue un análisis de las formas de segregación de contenidos en la práctica escolar (Cuervo Montoya), y un estudio del estado de la educación formal de los formadores de la Era Digital (Cabero Almenara \& Marín Díaz). Los escenarios online para el aprendizaje de un instrumento musical (Guillén Box \& Roig Vila) y la actitud de futuros maestros frente al uso de las TIC en Educación (Flores-Lueg) constituyen sendas atenciones de gran detenimiento sobre cuestiones de interés estratégico, pues la actitud puede muy mucho condicionar el ejercicio de la aptitud. Esta veta se profundiza con el análisis del desarrollo de competencias en la formación inicial del profesorado de Educación Secundaria en España (Domínguez Fernández, Ramírez-Fernández \& Ordóñez Olmedo); y el estudio de las competencias digitales del profesorado en el Marco del Espacio Europeo de Educación Superior (Alberola-Robles). Seguidamente se concreta el foco de atención en los PLE y OERHE, es decir, respectivamente, en su equivalente en lengua española, "Entornos Personales de Aprendizaje" y "Recursos Educativos en Abierto en Educación Superior" (Vázquez-Cano). Con todo ello analizado, podemos detenernos en el análisis de cuestiones que pueden ser metáfora y realidad al mismo tiempo de lo óptimo y lo pésimo que el uso de las TIC puede tener. Una de tales cuestiones es un grave problema que no debemos en modo alguno negligir, el Ciberbullying, aquí estudiado detenidamente desde la perspectiva de la violencia hacia la identidad a través de las TIC (Rioseco Pais \& Morgado Gallardo); y, la otra cuestión, es la Realidad Aumentada (RA) como tecnología emergente para la innovación educativa (Margarita Moreno Martínez, Leiva Olivencia \& López Meneses).

Consideramos firmemente que la investigación en innovación educativa como la que se contiene en este monográfico, además de atender a los docentes -formación, actitudes-, a los peligros y a los recursos positivos, debe tratar también de los discentes y analizar una cuestión tan importante -y preocupante-como los factores 
de la deserción estudiantil -en este caso centrada en una Facultad de las Unidades Tecnológicas de Santander, Bucaramanga, Colombia, como idóneo epítome de dificultades vencidas e innovación educativa puesta al servicio de tal objetivo- (Peña Torres, Sola Martinez \& López Nuñez). Es fundamental calibrar y canalizar adecuadamente la motivación, pues es un factor determinante en el aprendizaje (García-Jiménez). No deja de ser significativo en ello atender e incentivar el relato digital (Digital Storytelling) como elemento narrativo en el ámbito educativo (Rosales-Statkus \& Roig-Vila). En el conjunto de todo ello es fundamental el desarrollo de la inteligencia interpersonal e intrapersonal en Educación Primaria a partir del uso de Tecnologías de Información y Comunicación (Sebastián Heredero \& Garrido Ceballos). Finalmente, podemos sopesar con detalle las percepciones de las herramientas Web en los entornos inclusivos (Sampedro Requena \& Muñoz González) pues, de ese modo, se puede hacer copartícipe de la Educación y de la innovación en ella a todos los agentes.

En el presente monográfico hemos reunido una quincena de estudios derivados de sendas investigaciones que analizan con suma atención múltiples facetas de la materia que nos ocupa. Se trata de un fórum que examina detenida e interdisciplinariamente la cuestión, y se hace además profundo conocimiento que aporta a los investigadores autores de estos estudios la contrastada perspectiva internacional de la que gozan. En esta quincena de estudios se trata un caudal ingente de investigación cuantitativa y detallada que, lejos de quedarse en la simple consideración de los datos - lo cual ya sería encomiable per se pues aporta una excelente información sobre la materia-, constituye conocimiento propiamente dicho ya que permite la toma de la perspectiva de conjunto tan necesaria para comprehender adecuadamente la magnitud de la cuestión y proponer, al mismo tiempo, soluciones factibles y de base científica -incluso de utilidad para quienes deban tomar decisiones políticas atañentes a los sistemas educativos - para poder construir nuevos escenarios de enseñanza-aprendizaje, no sólo más que factibles, sino plenamente efectivos. 